\title{
Immunomodulatory effect of Nigella sativa seed extract in male rabbits treated with dexamethasone
}

\author{
J.A.A. Al-Sa'aidi ${ }^{1 *}$, Kh.A. Dawood ${ }^{1}$, A.D. Latif $^{2}$ \\ ${ }^{1}$ Department of Physiology and Pharmacology, Collage of Veterinary Medicine, Al-Qadisiya University, \\ ${ }^{2}$ Department of Pharmacology and Toxicology, Collage of Medicine, Wasit University, Iraq \\ *Email: jbr20042002@yahoo.com
}

\begin{abstract}
The potent ameliorating effect of ethanol extract of $N$. sativa seed on the immune system has been assessed in dexamethasone-induced immune-suppressed male rabbits. Fifty mature male rabbits were randomly assigned into five equal groups (control and four treated groups). Animals were daily treated, for 42 days, as follow: C: was orally administered with drinking water; $\mathrm{T}_{1}$ : was orally administered with N.s.S.E. $\left(1.5 \mathrm{~g} / \mathrm{kg}\right.$, b.w.); $\mathrm{T}_{2}$ : was injected with dexamethasone $(2 \mathrm{mg} / \mathrm{kg}$, b.w., im); $\mathrm{T}_{3}$ : was combined treated concomitantly with N.s.S.E. and dexamethasone; $\mathrm{T}_{4}$ : was treated with dexamethasone for 21 days followed by N.s.S.E. for 21 days. The results of body weight gain revealed significant increase in $\mathrm{T}_{1}$ and significant decrease in $T_{2}$ among the experimental groups. Submandibular lymph node weights of $T_{1}, T_{2}$ and $T_{3}$ were significantly higher than that of $C$. Kidneys weights in $T_{2}$ and $T_{3}$ registered significant increase compared with $C$. Bone weight in $T_{1}$ and $T_{4}$ groups was significantly higher than that of other groups. Liver weight in $T_{2}$ was significantly higher and in $T_{4}$ was significantly lower than other groups. Total leucocytes count and lymphocytes, monocytes and eosinophils percentages were significantly decreased in $T_{1}$, while showed no significant differences in $T_{2}, T_{3}$ and $T_{4}$ groups compared with that of control. Phagocytes activity and bone marrow mitotic index were significantly reduced in $T_{2}$ group, while returned to normal in $T_{1}, T_{3}$ and $T_{4}$ groups compared with control. Titers of $\operatorname{IgM}, \operatorname{IgA}, \mathrm{C}_{3}$, and $\mathrm{C}_{4}$ showed no significant differences among groups, while $\operatorname{IgG}$ titer was increased in $T_{1}$ and $T_{4}$ and decreased in $T_{2}$. On the basis of the results obtained, it can be concluded that the examined extract showed a certain immunomodulating effect. Of the immunological aspects, cellular immunity was potentially ameliorated in intact and dexamethasone-induced immunosuppressed- male rabbits.
\end{abstract}

Keywords: Nigella sativa; Dexamethasone; Immunomodulation.

Available online at http://www.vetmedmosul.org/ijvs

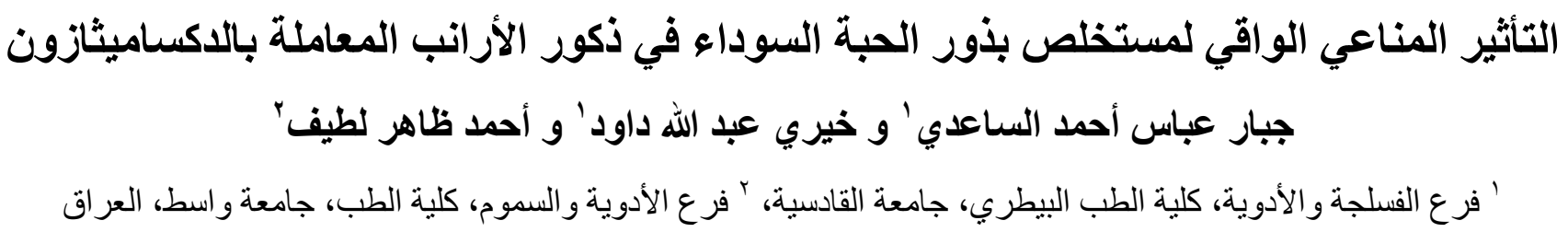

الخلاصة

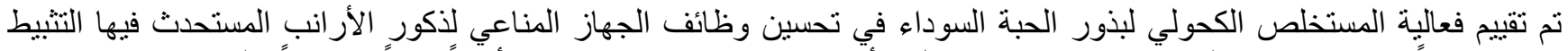

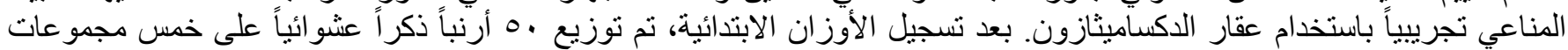

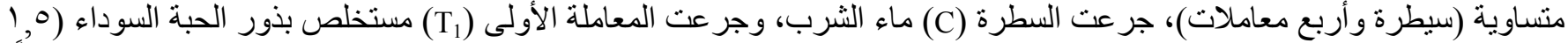

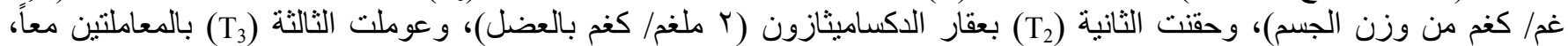

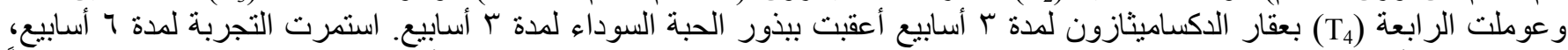

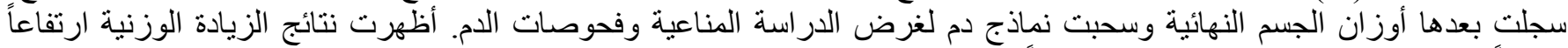

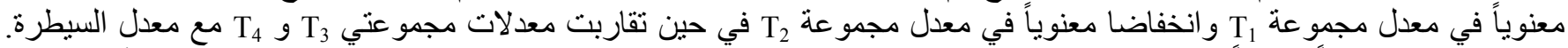

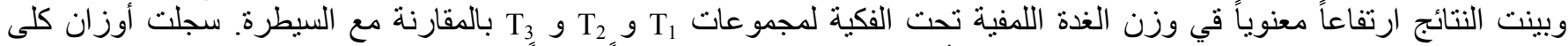

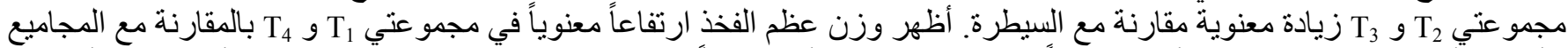

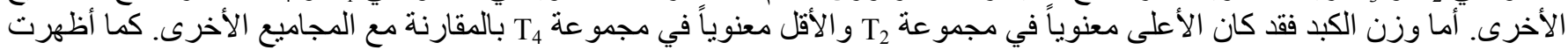




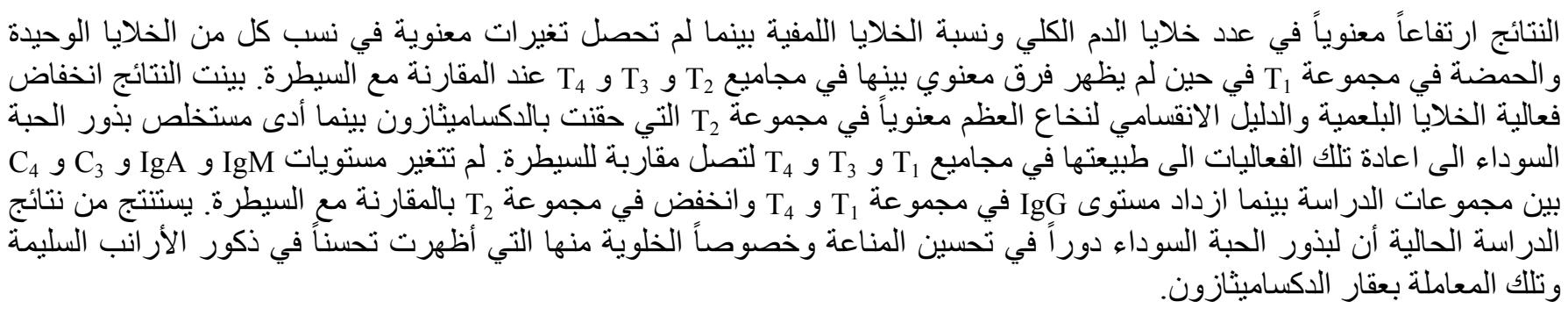

\section{Introduction}

Adrenocortical steroids used in medicine for their antiinflammatory and immune suppressive effects such as severe asthma, acquired hemolytic anemia, allergic reactions of all kinds, organ transplant rejection $(1,2)$. Dexamethasone is one of the several glucocorticoids were used experimentally for induce immunosuppression in many cases (3), but are responsible for some of adverse effects that were occur with large doses or prolonged administration which including suppression of the response to infection or injury and reduce function of osteoblast and unwanted side effects on the organ system and metabolic actions (4). Today world is increasingly seeking ways to replace the synthetic drugs with therapeutic power of natural products, the traditional folk medicine had already found the secret of healing in the nature. Medicinal plant have been used for therapeutic purposes since the beginning of civilization (5). Nigella sativa (black seed) is one of the most well known plants used in the history of mankind as a medicament or spice. It is an important medicinal herb in many Arabian, Asian, and African countries. It is used as a natural remedy for a variety of illnesses with important role to enhance human immunity $(6,7)$. The seed have combined effects nutritional and medicinal values, by the helping to relieve the current condition, also helps the body build further resistance against future diseases (8). Many studies recorded that black seed can be used as anti tumor, antiinflammatory, anti-diabetic, anti-oxidant, anti-histaminic, anti-microbial, anti-parasitic, analgesic and immunopotentiating $(9,10,11)$.

Thus, the present study was undertaken to assess the immunomodulatory effect of the crude ethanol extract of $N$. sativa seed in intact and dexamethasone-induces immunosuppressed male rabbits.

\section{Materials and methods}

\section{Preparing the Medicinal Herbs and extraction procedure:}

Dried seed of $N$. sativa were purchased from the local herbs store in Al-Kut city, Iraq. The seed has been classified by SBSTC (State Board for Seed Testing and Certification, Ministry of Agriculture, Iraq). The seed was completely cleaned and then turned into powder using an electrical grinder. The $1 \mathrm{~kg}$ powdered seed was defatted with $70 \%$ ethanol $\left(60-80^{\circ} \mathrm{C}\right)$ in a Soxhlet extraction apparatus (12). The yields of the extract was found to be $19.20 \% \mathrm{w} / \mathrm{w}$.

\section{Medical drug}

Dexamethasone sod. phosphate (Biodexasone, Germany) was used ( $2 \mathrm{mg} / \mathrm{kg}$, b.w., im) for induction of immune- suppression in rabbits (13).

\section{Experimental animals}

Male rabbits, weighting 1500- $1600 \mathrm{~g}$, bred in Animal House (College of Vet. Med., Al-Qadisiya Univ., Iraq) were used in the present study. The animals were fed on alfalfa and pellet diet as well as drinking water ad libitum. The animals were maintained at $23 \pm 2{ }^{\circ} \mathrm{C}$ with lights on for 12 h (700-1900) per day. Before experimentation, rabbits were acclimated for $2 \mathrm{wk}$, and the experiment began when the rabbits were 90 days old. Each day at 7 am, body weight was recorded and animals were treated.

\section{Methods}

Total leucocyte count (x 10\%/ L): according to (14). Differential Leucocytes Count (\%): according to (15). Phagocytes activity: according to (16). Bone Marrow Cellularity (Mitotic Index): according to (17). Erythrocytes Rosette Test: according to $(18,19)$. IgG, $\operatorname{IgM}, \operatorname{IgA}, \mathrm{C}_{3}$ and $\mathrm{C}_{4}$ assessment: according to the manufacturer instructions.

\section{Experimental design}

Fifty mature male rabbits were randomly assigned to five equal groups (control and four treatment groups); C: (10 male rabbits) were administered drinking water (orally) and injected with normal saline (i.m.) daily for 6 wks. $T_{1}$ : (10 male rabbits) were administered N.s.S.E ( $1.5 \mathrm{~g} / \mathrm{kg}$,b.w., orally) (20), and injected with normal saline (i.m.) daily for 6 wks. $T_{2}$ : (10 male rabbits) were administered drinking water (orally) and injected with dexamethasone Sod. Phosphate (2mg/ kg, b.w., i.m.) daily for 6 wks (13). $\mathrm{T}_{3}$ : (10 male rabbits) were administered N.s.S.E (1.5g/kg,b.w., orally) and injected concomitantly with dexamethasone Sod. Phosphate $\left(2 \mathrm{mg} / \mathrm{kg}, \mathrm{b} . w .\right.$, i.m.) daily for $6 \mathrm{wks}$. $\mathrm{T}_{4}$ : $(10$ male rabbits) were injected dexamethasone Sod. Phosphate 
( $2 \mathrm{mg} / \mathrm{kg}$,b.w., i.m.) daily for 3 wks and then administered N.s.S.E (1.5g/kg,b.w., orally) daily for further 3 wks.

At the end of the experimental period, final body weights were recorded and blood samples were obtained from marginal ear vein for hematological and immunological assays. Then male rabbits were sacrificed. Selected organs (lymph node, spleen, kidney, liver, and femoral bone) were removed and weighted. Femoral bones were used to study bone marrow mitotic activity.

\section{Statistical analysis}

All data were analyzed using one way analysis of variance; ANOVA-I and LSD for comparison between the experimental groups. level of 0.05 was considered for significance.

\section{Results}

\section{Body weight Gain (g.)}

Figure (1) revealed that $T_{1}$ male rabbits gained the highest body weight, while $\mathrm{T} 2, \mathrm{~T} 3$ and $\mathrm{T} 4$ registered the lowest gain compared with that of control.

\section{Organ weights (g./100g,b.w.)}

Table (1) show the results of organ weights. Liver of $T_{2}$ male rabbits registered the significantly highest weight compared with $T_{3}$ and $T_{4}$, whereas $T_{4}$ registered the lowest weight $(\mathrm{P}<0.01)$ compared with that of other three groups which showed no significant difference between them. Kidneys in $T_{2}$ and $T_{3}$ groups registered significantly $(\mathrm{P}<0.01)$ higher weight than $\mathrm{C}$ and $\mathrm{T}_{1}$ groups. Spleen weight showed no significant differences throughout experimental groups. Lymph node weight of $T_{1}$ and $T_{2}$ revealed no significant differences between each other, but they were significantly higher $(\mathrm{P}<0.01)$ than that of control group. Rabbits administered with N.s.SE alone $\left(\mathrm{T}_{1}\right)$ or with dexamethasone for 6 weeks $\left(\mathrm{T}_{4}\right)$ have been recorded the highest $(\mathrm{P}<0.01)$ bone weight, whereas those treated with dexamethasone $\left(\mathrm{T}_{2}\right)$ recorded the lowest mean value in comparison with that of control.

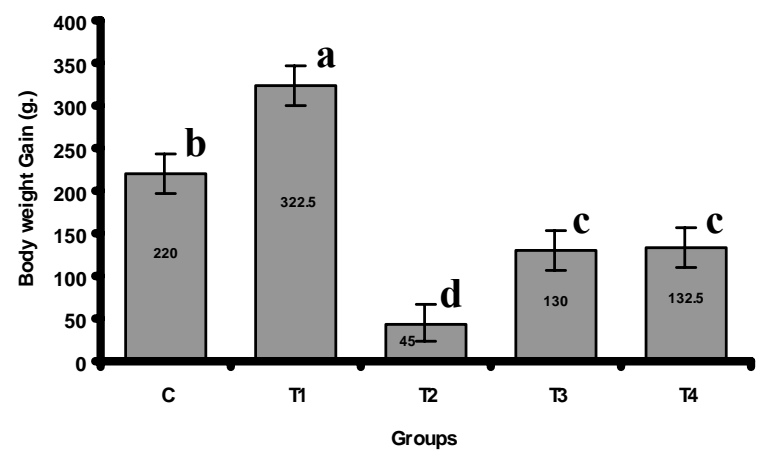

Fig. 1: Effect of N.s.S.E. and dexamethasone administration on B. Wt. gain (g.) in mature male rabbits. Values represents M. \pm S. E. for 5 rabbits/ group. Different small letters represent significancy at 0.01 level.

\section{Total Leucocytes Counts $\left(\times 10^{9} / \mathrm{L}\right)$}

Total leucocytes count shown in table (2) revealed that $\mathrm{T}_{1}$ and $\mathrm{T}_{3}$ registered the highest significant $(\mathrm{P}<0.01)$ mean values and $T_{2}$ male rabbits recorded the lowest significant values in comparison with control and $\mathrm{T}_{4}$ which showed no significant difference when compared with each other.

Table 1: Effects of the N.s.S.E. and Dexamethasone on the organs weight in mature male rabbits.

\begin{tabular}{lccccc}
\hline \multirow{2}{*}{ Weight (organ) } & $\mathrm{C}$ & $\mathrm{T}_{1}$ & $\mathrm{~T}_{2}$ & $\mathrm{~T}_{3}$ & $\mathrm{~T}_{4}$ \\
\cline { 2 - 5 } & $1.35 \mathrm{~b}$ & $1.92 \mathrm{a}$ & $1.05 \mathrm{c}$ & $1.23 \mathrm{bc}$ & $1.69 \mathrm{a}$ \\
Bone weight $(\mathrm{g} / 100 \mathrm{~g})$ & \pm 0.06 & \pm 0.08 & \pm 0.11 & \pm 0.04 & \pm 0.04 \\
Lymph nodes weight & $0.112 \mathrm{c}$ & $0.122 \mathrm{~b}$ & $0.124 \mathrm{ab}$ & $0.13 \mathrm{a}$ & $0.117 \mathrm{bc}$ \\
(g/100g) & \pm 0.002 & \pm 0.003 & \pm 0.003 & \pm 0.004 & \pm 0.003 \\
Spleen weight & 0.050 & 0.063 & 0.060 & 0.061 & 0.053 \\
(g/100g) & \pm 0.001 & \pm 0.003 & \pm 0.003 & \pm 0.003 & \pm 0.003 \\
Kidney weight & $0.62 \mathrm{~b}$ & $0.61 \mathrm{~b}$ & $0.81 \mathrm{a}$ & $0.76 \mathrm{a}$ & $0.66 \mathrm{~b}$ \\
(g/100g) & \pm 0.02 & \pm 0.01 & \pm 0.02 & \pm 0.03 & \pm 0.03 \\
Liver weight $(\mathrm{g} / 100 \mathrm{~g})$ & $3.40 \mathrm{a}$ & $3.24 \mathrm{bc}$ & $4.08 \mathrm{a}$ & $3.47 \mathrm{~b}$ & $2.92 \mathrm{c}$ \\
& \pm 0.15 & \pm 0.11 & \pm 0.10 & \pm 0.21 & \pm 0.06 \\
\hline
\end{tabular}

Values represents M. \pm S. E. for 5 rabbits/ group, Different small letters represent significancy at 0.01 level. 
Table 2: Effects of N.s.S.E. and Dexamethasone on total and differential leucocytes count in mature male rabbits.

\begin{tabular}{lccccc}
\hline \multirow{2}{*}{ Leucocyte } & \multicolumn{3}{c}{ Groups of animals } & \\
\cline { 2 - 5 } & $\mathrm{C}$ & $\mathrm{T}_{1}$ & $\mathrm{~T}_{2}$ & $\mathrm{~T}_{3}$ & $\mathrm{~T}_{4}$ \\
\hline Total Leucocyte count & $1451 \mathrm{~b}$ & $1946 \mathrm{a}$ & $1038 \mathrm{c}$ & $1971.4 \mathrm{a}$ & $1535 \mathrm{~b}$ \\
$\left(\times 10^{9} / \mathrm{L}\right)$ & \pm 44.38 & \pm 81.43 & \pm 80.41 & \pm 89.09 & \pm 45.34 \\
Neutrophils \% & $47.1 \mathrm{c}$ & $45.6 \mathrm{c}$ & $67.3 \mathrm{a}$ & $53.9 \mathrm{~b}$ & $51.6 \mathrm{~b}$ \\
& \pm 0.67 & \pm 1.09 & \pm 0.8 & \pm 1.56 & \pm 1.48 \\
Lymphocytes & $41.7 \mathrm{~b}$ & $45.1 \mathrm{a}$ & $27.9 \mathrm{~d}$ & $37.0 \mathrm{c}$ & $39.4 \mathrm{bc}$ \\
& \pm 0.54 & \pm 0.91 & \pm 1.00 & \pm 0.80 & \pm 0.56 \\
Monocytes \% & $7.40 \mathrm{a}$ & $7.3 \mathrm{a}$ & $3.5 \mathrm{~b}$ & $7.2 \mathrm{a}$ & $6.0 \mathrm{ab}$ \\
& \pm 0.62 & \pm 0.87 & \pm 0.52 & \pm 0.88 & \pm 0.97 \\
Eosinophils \% & $3.0 \mathrm{a}$ & $1.7 \mathrm{ab}$ & $0.9 \mathrm{~b}$ & $1.6 \mathrm{ab}$ & $2.5 \mathrm{a}$ \\
& \pm 0.42 & \pm 0.42 & \pm 0.23 & \pm 0.52 & \pm 0.50 \\
Basophils \% & 0.8 & 0.3 & 0.3 & 0.3 & 0.5 \\
& \pm 0.25 & \pm 0.21 & \pm 0.15 & \pm 0.15 & \pm 0.17 \\
\hline
\end{tabular}

Values represents M. \pm S. E. for 5 rabbits/group, Different small letters represent significancy at 0.01 level.

\section{Differential Leucocytes Counts}

Results clarified in table (2) showed significant increase $(\mathrm{P}<0.01)$ in neutrophils percentage of $\mathrm{T}_{2}, \mathrm{~T}_{3}$ and $\mathrm{T}_{4}$ compared with control and $\mathrm{T}_{1}$ groups. $\mathrm{T}_{2}$ recorded the highest percentage among the experimental groups. Lymphocytes in $\mathrm{T}_{1}$ recorded the highest significant percentage whereas $T_{2}$ recorded the lowest percentage. Monocytes in $T_{2}$ recorded the lowest significant percentage among the experimental groups. Eosinophils in $T_{2}$ group recorded the highest significant percentage among the experimental groups.

\section{Phagocytes activity (\%)}

Phagocytes indices (\%) shown in figure (2) revealed that male rabbit of $\mathrm{T}_{4}$ registered the highs percentage followed by control, $\mathrm{T}_{1}, \mathrm{~T}_{3}$ and $\mathrm{T}_{2}$, respectively.

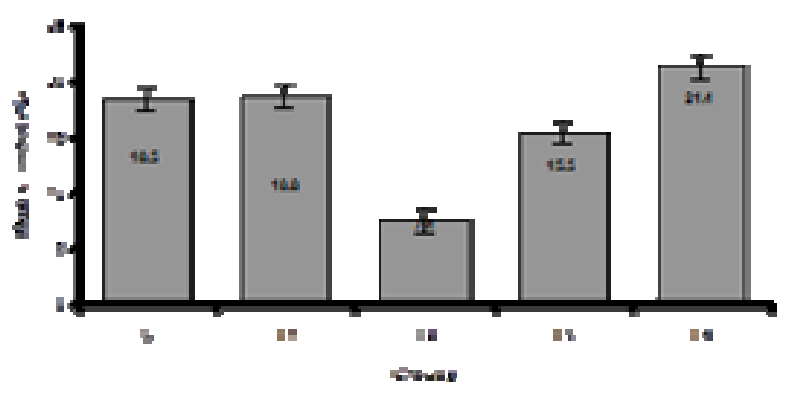

Fig. 2: Effect of N.s.S.E. and dexamethasone on Phagocytic activity in mature male rabbits. Values represents M. $\pm \mathrm{S}$. E. for 5 rabbits/ group. Different small letters represent significancy at 0.01 level.

\section{Bone marrow mitotic index (\%)}

Male rabbits of $\mathrm{T}_{1}$ and $\mathrm{T}_{4}$ groups registered no significant percentage of bone marrow mitotic activity, whereas $T_{2}$ and $T_{3}$ groups registered lower significant $(\mathrm{P}<0.01)$ percentage of mitotic activity compared with that of control (figure 3 ).

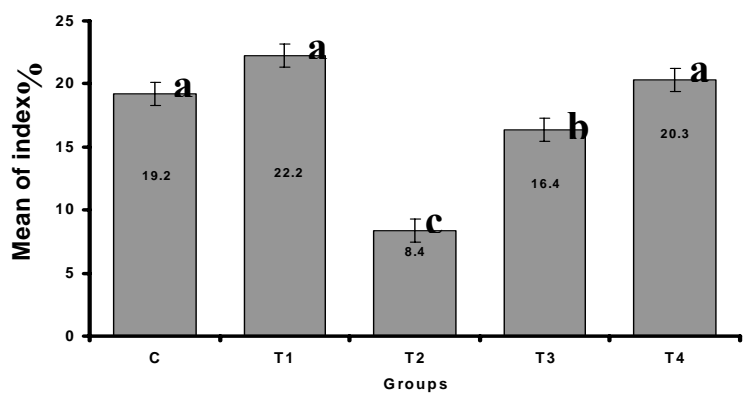

Fig. 4: Effect of N.s.S.E. and dexamethasone on bone marrow mitotic index in mature male rabbits. Values represents M. \pm S. E. for 5 rabbits/ group. Different small letters represent significancy at 0.01 level.

\section{Erythrocyte Rosette Test}

Findings of active E.R.I. revealed that $\mathrm{T}_{2}$ group recorded significant decrease $(\mathrm{P}<0.01)$ among the experimental groups. On the other hand, total E.R.I. results showed that $\mathrm{T}_{1}$ male rabbits recorded the highest mean value, followed by $T_{3}$ and $T_{4}$ and control which showed no significant differences between each other, whereas $T_{2}$ group male rabbits recorded the lowest mean value (figure 6). 

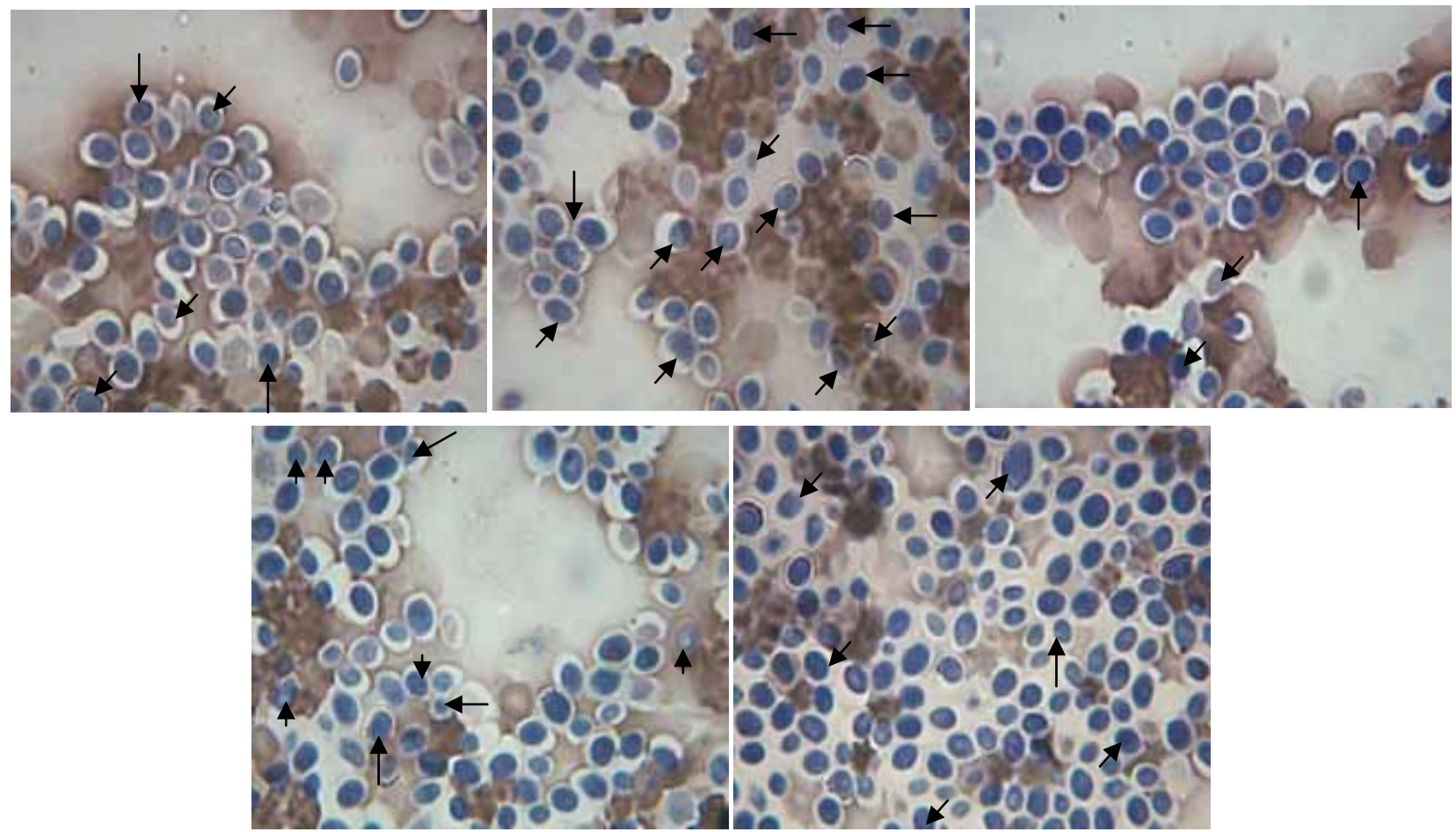

Figure 3: Effect of N.s.S.E. and dexamethasone on phagocytes activity in mature male rabbits. Pointed with arrows show that monocytes (blue color) and phagocytes contain yeast (pink-red color).

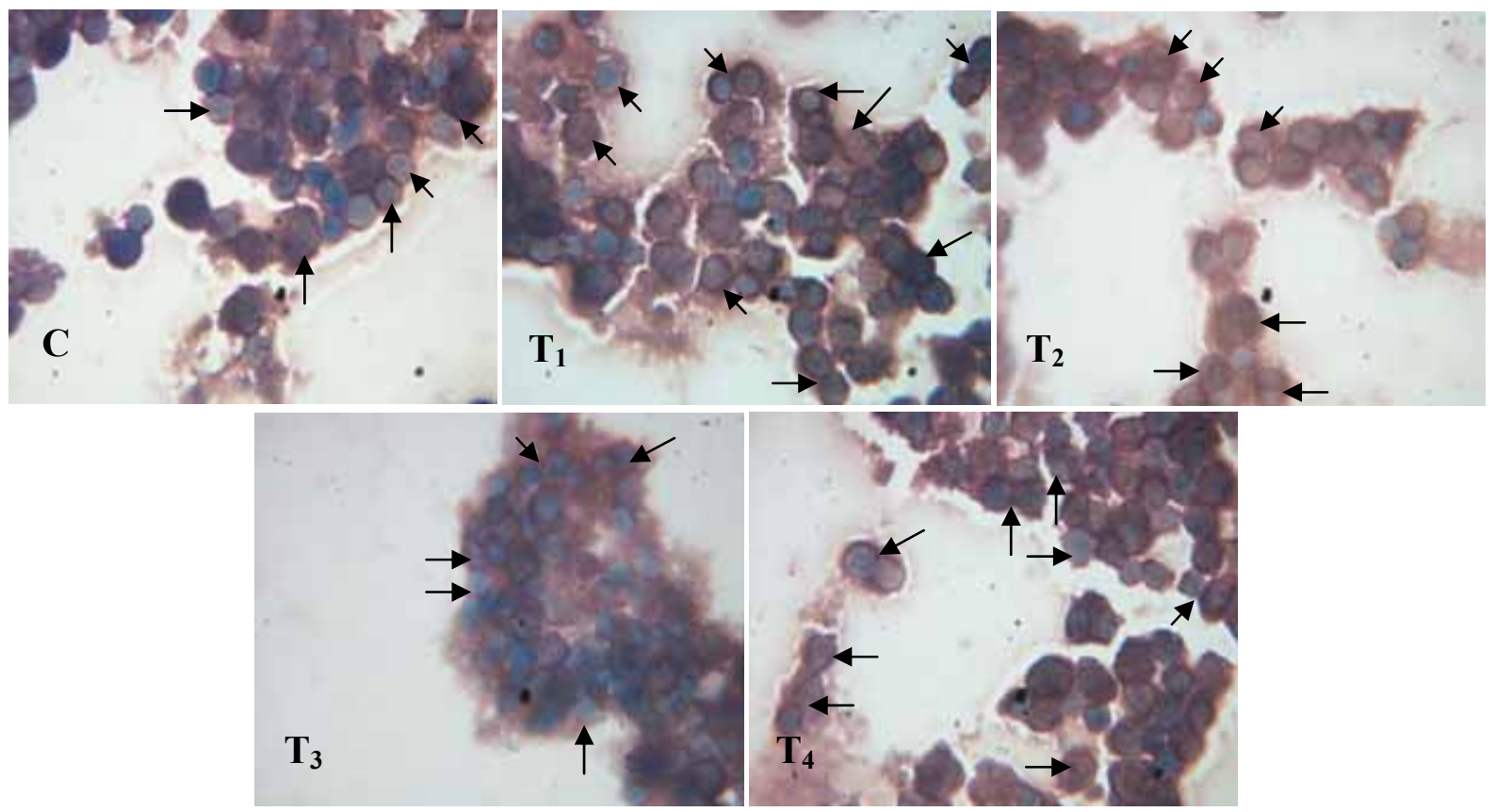

Figure 5: Effect of N.s.S.E. and dexamethasone on Bone marrow mitotic index activity in mature male rabbits (pointed with arrows). 

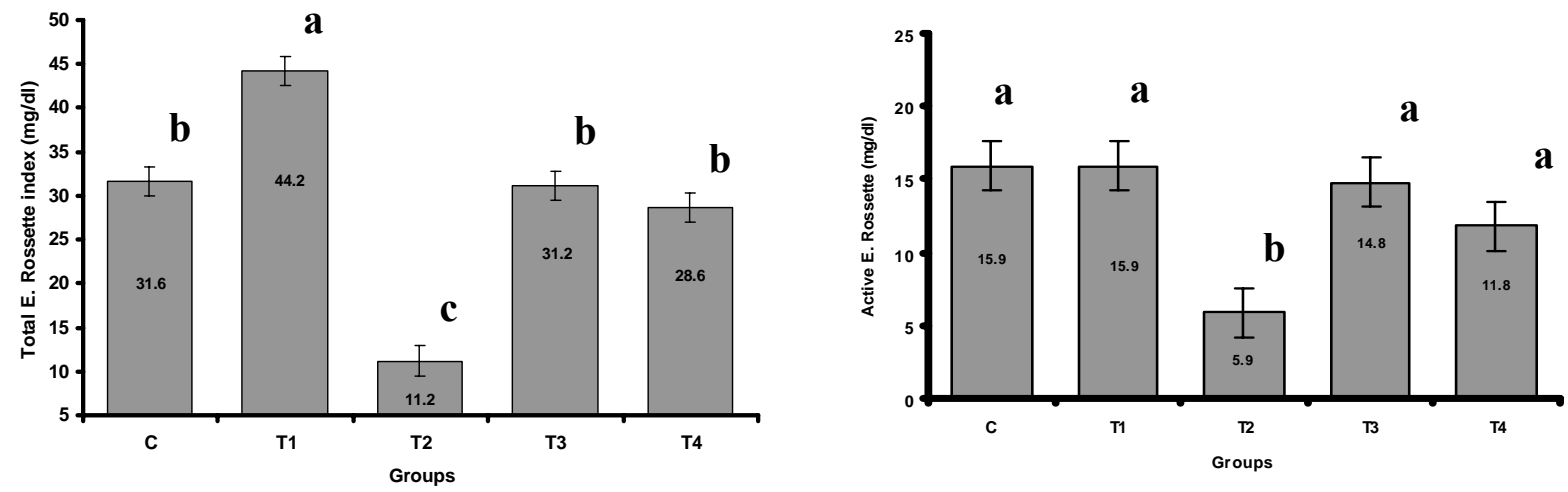

Figure 6: Effect of N.s.S.E. and dexamethasone on active and total E.R.I in mature male rabbits. Values represents M. \pm S. E. for 5 rabbits/ group. Different small letters represent significancy at 0.01 level.
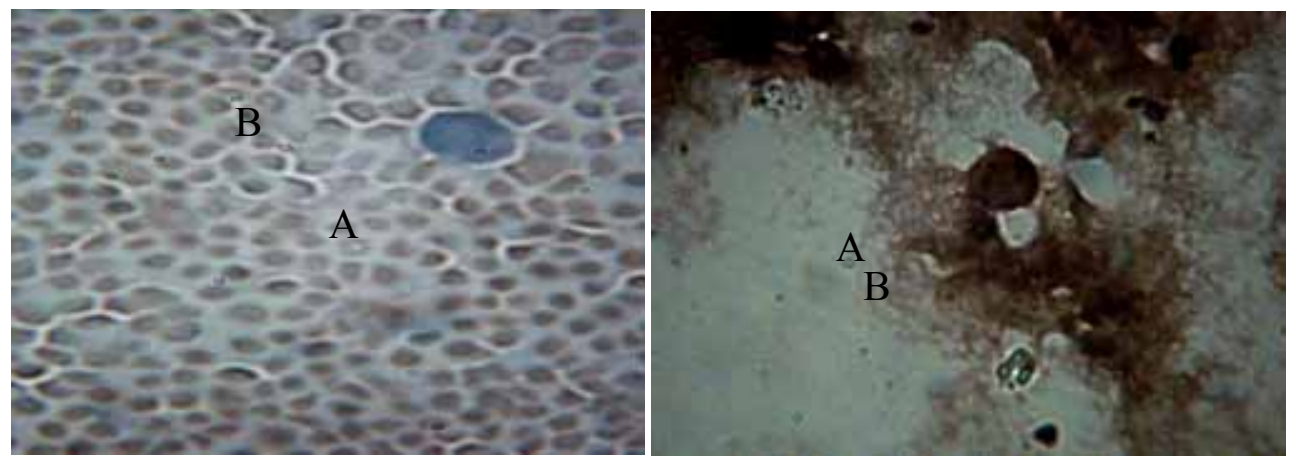

Figure 7: Effect of N.s.S.E. and dexamethasone on active and total E.R.I in mature male rabbits. Left (active E. R. test, Trypan blue stain). Right (total E. R. test Giemsa stain). (A) represent monocyte cell (Rabbit) and (B) represent Sheep RBC. Pointed arrow represent $E$. rossette formation.

\section{Immunoglobulin titers $(\mathbf{m g} / \mathbf{d l})$}

Results of immunoglobulin titers shown in table (3) revealed significant decrease $(\mathrm{P}<0.01)$ in IgG titer of $\mathrm{T}_{2}$ and $\mathrm{T}_{3}$ male rabbits compared with $\mathrm{T}_{4}$, whereas that of $\mathrm{T}_{1}, \mathrm{~T}_{4}$ male rabbits recorded no significant differences compared with that of control. On the other hand, IgM and IgA titers recorded no significant differences between groups of the experiment.

\section{Complements titers (mg/dl)}

Complement titers $\left(\mathrm{C}_{3} \& \mathrm{C}_{4}\right)$ recorded no significant differences $(\mathrm{P}>0.01)$ among the experimental groups when compared with each other (table 4).

Table 3: Effects of the N.s.S.E. and dexamethasone on Immunoglobulin titers (IgG, $\operatorname{IgM}, \operatorname{IgA})$ in mature male rabbits.

\begin{tabular}{lccccc}
\hline Groups & $\mathrm{C}$ & $\mathrm{T}_{1}$ & $\mathrm{~T}_{2}$ & $\mathrm{~T}_{3}$ & $\mathrm{~T}_{4}$ \\
\hline IgG & $2829.81 \mathrm{a}$ & $3113.77 \mathrm{a}$ & $1909.41 \mathrm{c}$ & $2311.53 \mathrm{~b}$ & $3072.66 \mathrm{a}$ \\
Titer $(\mathrm{mg} / \mathrm{dl})$ & \pm 79.45 & \pm 92.78 & \pm 71.81 & \pm 157.69 & \pm 124.38 \\
IgM & 7.26 & 9.68 & 7.26 & 4.84 & 12.1 \\
Titer $(\mathrm{mg} / \mathrm{dl})$ & \pm 3.70 & \pm 3.95 & \pm 3.70 & \pm 3.23 & \pm 4.03 \\
IgA & 4.7 & 18.8 & 9.4 & 4.7 & 14.1 \\
Titer $(\mathrm{mg} / \mathrm{dl})$ & \pm 4.7 & \pm 7.68 & \pm 6.27 & \pm 4.7 & \pm 7.18 \\
\hline
\end{tabular}

Values represents M. \pm S. E. for 5 rabbits/group. Different small letters represent significancy at 0.01 level. 
Table 4: Effects of N.s.S.E. and dexamethasone on the complements titer $\left(\mathrm{C}_{3} \& \mathrm{C}_{4}\right)$ in mature male rabbits.

\begin{tabular}{lccccc}
\hline Groups & $\mathrm{C}$ & $\mathrm{T}_{1}$ & $\mathrm{~T}_{2}$ & $\mathrm{~T}_{3}$ & $\mathrm{~T}_{4}$ \\
\hline $\mathrm{C}_{3}$ & 307.68 & 320.04 & 304.85 & 309.24 & 322.42 \\
Titer $(\mathrm{mg} / \mathrm{dl})$ & \pm 6.23 & \pm 7.48 & \pm 9.43 & \pm 8.85 & \pm 4.77 \\
$\mathrm{C}_{4}$ & 93.24 & 85.14 & 78.9 & 86.82 & 82.85 \\
Titer $(\mathrm{mg} / \mathrm{dl})$ & \pm 3.85 & \pm 5.77 & \pm 3.99 & \pm 4.95 & \pm 6.16 \\
\hline
\end{tabular}

Values represents M. \pm S. E. for 5 rabbits/group. Different small letters represent significancy at 0.01 level.

\section{Discussion}

Rabbits have been used in the present study as experimental model for mammals, because rabbits are often used as animal model for experimental purposes in human and veterinary researches, such as immunosuppression, as indicated by (3) and (11). Also the present study was conducted by using dexamethasone sodium phosphate as immunosuppressant drug, which may affect cellular and humoral immunity (14), to examine the role of Nigella sativa seed extract in ameliorating the adverse effects of the drug. Regarding the safety of $N$. s., its seeds extract did not produce any adverse effect in the present study, rather it provided potent role. The safety of $N$. s. has been mentioned by other research (21).

Because dexamethasone may indirectly affect the endocrine response (22) through its effect on the satiety center of the hypothalamus as a result of high level of glucose in the glucose sensitive neurons (23), body weight gain was affected in dexamethasone treated groups. On the other hand, dexamethasone may alter the carbohydrate metabolism which may lead to increase glucose utilization (glyconeogenesis) with glucose urea and it's effect in the protein metabolism (anabolism) (conversion of amino acid to protein) was decrease but the catabolism continues or even faster (1). Our results revealed improvement of body weight gain in male rabbits administrated with N.s.S.E. with or without dexamethasone. These findings may attributed to the nutritional value of N.s. seed, particularly the seed is rich in essential and non essential amino acids, fatty acids and other building blocks for the body such as carbohydrates, protein, fat, vitamins and minerals $(24,25,26)$. It has been shown that effect of N.s. seed, as nutritional and medicinal value, may attributed to improving digestion and providing quick energy and increasing body tone $(8,27)$.

Rabbits treated with dexamethasone recorded significant increase in the liver, kidney and lymph node weight. This result was in agreement with $(3,28)$, whom demonstrated the ability of dexamethasone to increase accumulation and degranulation of leukocytes inflammatory focus. This increment may be due to proliferative lesion and hyperplasia in these organs, or due to migration of eosinophils, basophils, monocytes and lymphocytes from circulation to lymphoid tissues. Many researchers demonstrated that chronic administration of corticosteroid may cause bone fragility and osteoporosis (reduction of bone protein matrix) $(29,30)$. Kondo et al (31) attributed the decrement of bone weight primarily to the hypofunction and apoptosis, and secondarily to acceleration of bone resorption and stimulation of osteoclastogenesis. Sivagurunathan et al. (30) showed that dexamethasone sitmulated osteoclast generation at a pharmacological concentration but did not affect in the span of human osteoclasts and dose- dependently increased signal for osteoclasteogenesis.

N.s.S.E. treated groups showed protective action reflected by improvement of organ weights. This result was in agreement with $(5,9,14,32)$ whom reported the potential effects of N.s.S.E. against hepatic and renal damage induced by drugs (Like anticancer) and some toxin (Like carbon tetrachloride), as well as its activity in the prevention of liver fibrosis and cirrhosis in rabbits (33). The possible mode of action may be due to its main constituents thymoquinone, nigellone and d-limonene through their antioxidant and anti-inflammatory activities, coupled with enhancement of detoxification processes (34). Ali and Blunden (35) and Naji et al (36) attributed the protective activity of N.s.S against nephrotoxicity and hepatotoxicty induced by either disease or chemicals to the effect of thymoquinone via antioxidant mechanism.

Male rabbits treated with dexamethasone showed significant decrease in total Leukocytes and percentages of lymphocytes, monocytes and eosinophils with significant increase of neutrophils. This result was in agreement with the study of $(14,37)$ whom reported the inhibitory effect of glucocorticoides in the number and activity of $\mathrm{T}$ lymphocytes and in agreement with $(38,39)$ whom determined the redistribution of lymphocytes labelled with fluorescent isothiocyanate. Jeklova et al (3) detected peripheral blood neutrophilia and lymphopenia together with eosinopenia, monocytopenia and basopenia in rabbits after administration of dexamethasone.

These effects may results from the oxidative damage that affect the biological structures. The toxicity- induced pathophysiology of several disease, has been reported to be due to the shift in the balance of the pro-oxidant (Free radicals) and the antioxidant (scavenging) mediators, where pro-oxidant conditions dominate either due to increase generation of free radicals caused by excessive oxidative 
stress, or due to the poor scavenging capability in the body (40) that may be lead to decrease in the lymphocytes due to immunosuppressive ability of glucocorticoides in the reduction of T- lymphocyte proliferation via mechanisms that are at least partially the result of inhibition of the Tcell growth factor $\mathrm{IL}_{2}$ and blocking a cell cycle progression (41).

The activity of the extract to reduce the adverse effects of dexamethasone may attributed to the ability of the N.s.S. proteins to enhance the production of IL-3 and IL-1 by lymphocytes, as it has been proved when cultured with or without allogenic cell (40). Haq et al (42) reported increase in the macrophage, monocytes and T-cells percentage and its activity to secrete interleukin with significant decrease in the neutrophils when used volatile oil of N.s.S. (43) reported that the effects of N.s. is due to its biochemical, immunological and pharmacological actions as antiinflammatory and immunopotentiating through its effects on the DNA synthesis, cell proliferation and the ability of scaveringing superoxide radicals. Corder et al., (44) and Musa et al., (45) showed that exposure of black seed to cell pretreated with cortisol show evidence of protection against the progressive apoptosis, so can play therapeutic roles in reducing anti-inflammatory and anti-oxidant effects with enhancement of detoxification process. Whereas Salem (40) suggested that immune-enhancing effect of N.s. on cellmediated immunity due to its ability to reduce the inflammatory mediators.

Present study reported significant decrease in phagocytic activity of the cells in rabbits treated with dexamethasone which may due to its inhibitory effect upon neutrophil function, particularly those have undergone priming of activation like phagocytosis or nitric oxide release (46) or due to stress that alters neutrophil function (3). Male rabbits treated with N.s.S.E. reported increment in the phagocytic activity due to the role of N.s. in stimulating the immune cells and increase the activity of immune potential (5). Antioxidant and anti-inflammatory activity of the $N$. s. may protect the phagocytic cell $(40,47)$ or by the effect of N.s. on the DNA synthesis during cell proliferation and the ability of scavenging the super oxide radicals (45).

\section{References}

1. Bennett, P. and Brown, M. (2003). Clinical pharmacology. 9th. (eds.). Churchill Livingstone., pp:663- 675.

2. Katzung, B. (2007). Basic pharmacology. $10^{\text {th }}$. (eds.). Mc Graw Hill. USA.

3. Jeklova, E.; Leva, L.; Jaglic, Z. and Faldyna, M. (2008). Dexamethasone- induced immunosuppression: a rabbit model. Veterinary Immunology and Immunopathology. 122:231- 240.

4. Rang, H.; Dale, M.; Ritter, J. and Flower, R. (2007). Rang and Dales Pharmacology. $6^{\text {th }}$. (eds.). Elsilver Co., London.

5. Sogut.; Celik, I. and Tuluce, Y. (2008). The effect of diet supplemented with the black cumin (Nigella sativa L.) upon immune potential and antioxidant marker enzymes and lipid peroxidation in broiler chicks. J. Animal and Veterinary advances. 7(10):1190- 1199.

6. Meral, I.; Yener, Z.; Kahraman, T. and Mert, N. (2001). Effect of Nigella sativa on glucose concentration, lipid peroxidation, antioxidant defense system and liver damage in experimentally induced diabetic rabbits. J. Vet. Med. 48(10):593- 599.

7. Kalus, U.; pruss, A.; Bystron, J.; Jureck, M.; smekalova, A.; Lichius, J. and Kiesewetter, H. (2003). Effect of Nigella sativa (black seed) on Subjective Feeling in patients with allergic diseases. Phytother Res. 17(10):1209- 1214

8. Salem, M. and Hussain, M. (2000). Protective Effect of black seed oil from Nigella Sativa against murine Cytomegalo virus Infection. J. Immunopharmacology. 22(9):729- 740.

9. Taskin, M.; Gazar, H.; Khan, I. and Bedir, E. (2005). Triterpene Saponins from Nigella Sativa L. Turk J. Chem. 29:561- 569.

10. AL-Ali, A.; Alkhawajah, A.; Randhawa, M. and Shaikh, N. (2008). Oral and Intraperitoneal $\mathrm{LD}_{50}$ of Thymoquinone, An Active principle of Nigella Sativa in mice and Rats.J. Ayub. Med. Coll. Abbottabad., $20(2): 15-19$.

11. Randhawa, M. (2008). Black seed, Nigella Sativa, Deserves more attention. J. Ayub Med. Coll Abbottabad. 20(2):15- 18.

12. Harborne, J. (1984). Textbook of phytochemical Methods. AGuide Modern Techniques of plant Analysis $2^{\text {nd }}$. (eds.). London. pp:195- 198.

13. Jeklova, E.; Leva, L. and Faldyna, M. (2007). Lymphoid organ development in rabbits: Major Lymphocyte Subsets. Dev. Comp. Immunol. 31:632- 644 .

14. Dacie, J. and Lewis, S. (1984). Practical Haematology. $6^{\text {th }}$ (eds.). Churchill Livingstone. pp:40- 55.

15. Schalm, O. (1965). Vetevinary Hematology. Febiger, Philadelphia. pp:664.

16. Weber, B.; Nickol, M.; Jagger, K. and Saelinger, C. (1982). Interaction of pseudomonas as exproducts with phagocytic cell. Can. J. Microbio.; 28:679- 685.

17. Savage, J. (1975). Classification and relationships of induced chromosomal stractural changes. J. Med. Genetics. 12:103- 122.

18. Braganza, C.; Stathopoulos, G.; Davies, A.; Elliott, E. and Kerbel, R. (1975). Lymphocyte: Erthrocyte (L.E.) Rosettes as Indicators of the heterogeneity of Lymphocytes in avariety of mammalian species. Cell., 4:103- 106.

19. Mackenzie, L. (1998). Rosetting techniques. In:Delves, P.J. and Roitt, I.M. (eds.). Encyclopedia of Immunology. Academic perss. London, U.K. pp:1- 11.

20. Al-Sa'aidi, J.A.A.; Al-Khuzai, A.L.D.; Al-Zobaydi, N.F.H. (2009). Effect of alcoholic extract of Nigella sativa on fertility in male rats. Iraqi Journal of Veterinary Sciences, Vol. 23, Supplement II, 2009 (123-128).

21. Zaoui, I.; cherrah, Y.; Mahassini, N.; Alaoui, K.; Amar ouch, H. and Hassarssue, M. (2002). Acute and chronic toxicity of Nigella Sativa fixed oil. Phytomedicine. 9(1):3- 6 .

22. Smith, C.; Erasmus, P. and Myburgh, K. (2006). Endocrine and immune effects of dexamethasone in unilateral total Knee replacement. J. Int. Med. Res. 34(6):603- 611.

23. Oomura, Y. (1987). Regulation of Feeding by neural responses to endogenous factors. News physiol. Sci. 2:199- 203.

24. AL-Gaby, A.M. (1999). Amino acid composition and biological effects of supplementing broad bean and corn proteins with Nigella sativa (black Cumin) cake protein. Nahrung., 42 (5): 290- 294.

25. Swami, S. and Tan, B. (2000). Cytotoxic and immunopotentiating effects of ethanolic extract of Nigella Sativa L. seeds. J. Ethnopharmacology. 70(1):1- 7 .

26. Ahmad, Z.; Ghafoor, A. and Aslam, M. (2004). Introduction of medicinal herb and spices as Crop. Ministry of food, Agriculture and Livestock, Pakistan.

27. Ramadan, M. (2007). Nutritional value. Functional properties and nutraceutical applications of black cumin (Nigella Sativa L.): an Overview. J. Food science and Technology. 42:1208- 1218. 
28. Klymenko, M. and Kozyrieva, H. (2002). Effect of Dexamethasone on mast cell reaction in inflammation. Fiziol Zh. 48(3):29- 33.

29. Hirayama, T.; Sabokbar, A. and Athanasou, N. (2002). Effect of corticosteroids on human osteoclast formation and activity. J. Endocrinol., 175(1):155- 163.

30. Sivagurunathan, S.; Muir, M.; Brennan, T.; Seale, J. and Mason, R. (2005). Influence of glucocorticoids on human osteoclast generation and activity. J. Bone Miner Res. 20(3):390- 398.

31. Kondo, T.; Kitazawa, R.; Yamaguchi, A. and Kitazawa, S. (2008). Dexamethasone promotes osteoclastogenesis by inhibiting osteoprotegerin through multiple Levels. Cell Biochem. 103(1):335345.

32. Mohamed, A.; Metwally, N. and Mahmoud, S. (2005). Sativa seeds against Schistosoma mansoni different stages. Mem. Inst. Oswaldo. Cruz. 100(2):205- 211.

33. Maraqa, A.; AL-Sharoa, N.; Farah, H. and EL-Bjeirami, W. (2007). Effect of Nigella sativa extract and oil on aflatoxin production by Aspergillus flavus. J. Turk Biol. 31:155- 159.

34. EL-Dakhakhany, M.; Mady, N. and Halim, M. (2000). Nigella sativa L. oil protectagainst $\mathrm{CCL}_{4}$ and $\mathrm{D}$ - galactosamine induced hepatotoxicity and improves serum lipid profile in rats. Arzeimittel forschung. 50(9):832- 836.

35. Ali, B. and Blunden, G. (2003). Pharmacological and toxicological properties of Nigella sativa. Phytother. Res., 17:299-305.

36. Naji, M.; Alam, K. and Badary, O. (1999). Thymoquinone protects against carbon tetrachloride hepatotoxicity in mice via antioxidant mechanism. Biochemistry and Molecular biology International. 47(1):153-159.

37. Liberman, A.; Druker, J.; Refojo, D.; Holsboer, F. and Arzt, E. (2009). Glucocorticoids inhibit GATA-3 phosphorylation and activity in Tcells. J. Faseb. 23(5):1558- 1571.
38. Bloema, E.; weinrich, S. and Schellekens, T. (1990). The influence of prednisolone on the recirculation of peripheral blood Lymphocytes in ViVo. Clin. Exp. Immunol. 80:460-466.

39. Toft, P.; Tonnesen, E.; sevendsen, P.; Rasmussen, J. and Christensen, N. (1993). Redistribution of lymphocytes after major surgical stress. Acta Anaesthesial. Scand. 37:245- 249.

40. Salem, M. (2005). Immunomodulatory and therapeutic properties of the Nigella sativa L. seed. J. International Immunopharmacology. 5:1749- 1770 .

41. Newton, R. (2000). Molecular mechanisms of glucocorticoid action: what is important?. Thorax. 55:603- 613.

42. Haq, A.; Abdullatif, M.; Lobo, P.; Khabar, K.; Sheth, K. and ALSedairy, S. (1995). Nigella Sativa: effect on human lymphocytes and polymorphonuclear Leukocyte phagocytic activity. Immunopharmacology. 30(2):147- 155.

43. Winkler, C.; Schroecksnadell, K.; Ledochowski, M.; schennach, H.; Houcher, B. and Fuchs, D. (2008). Invitro effects of Nigella Sativa seeds extracts on stimulated peripheral blood mononuclear cells. Pteridines. 19(4): 101- 106.

44. Corder, C.; Benqhuzzi, H.; Tucci, M. and Cason, Z. (2003). Delayed apoptosis upon the treatment of Hep- 2 cells with black seed. Bio. Med. Sci. 39:365-370.

45. Musa, D.; Duisiz, N.; Gumushan, H.; Ulakoglu, G. and Muharrem, B. (2004). Antitumor activity of an ethanol extract of Nigella Sativa seeds. Biologia Bratislava. 59:635- 670.

46. Goulding, N.; Euzger, H.; Butt, S. and perretti, M. (1998). Novel pathways for glucocorticoid effects on neutrophils in chronic inflammation. Inflammation. Inflamm. Res. 47(3):5158- 5165.

47. Abdulelah, $\mathrm{H}$ and Zainal- Abidin, B. (2007). In vivo anti-malarial tests of Nigella sativa (Black seed) different extracts. Am. J. Pharmacol. and Toxicol., 2 (2): 46-50. 